\title{
Edmund Husserl y Jean-Paul Sartre: \\ apuntes sobre conciencia de imagen, fantasía e imaginación
}

\section{Edmund Husserl and Jean-Paul Sartre: notes on consciousness of image, phantasy and imagination}

DOI: 10.12957/ek.2020.50063

\author{
Sergio González Araneda \\ Universidad de Santiago de Chile \\ sgonzalezaraneda@gmail.com \\ https://orcid.org/0000-0003-2109-1389
}

\section{Resumen}

La fenomenología de la imagen y la teoría fenomenológica de la imaginación son derivas relativamente nuevas. En 1980 es publicada por vez primera Husserliana XXIII, texto que reúne los principales escritos de Husserl en relación a las temáticas de conciencia de imagen, phantasie y recuerdo. No obstante, la preocupación sobre la fenomenología de la imagen está presente desde los primeros textos de Husserl. En este contexto, el presente artículo pretende mostrar el sentido intencional que otorga el padre de la fenomenología a dichos conceptos y, con esto, exponer las falencias de la propuesta husserliana advertidas por Sartre, específicamente, aquello que el

Abstract

The phenomenology of the image and the phenomenological theory of the imagination are relatively new drifts. In 1980 Husserliana XXIII was published for the first time, a text that brings together the main writings of Husserl in relation to the themes of image consciousness, phantasy and memory. However, the concern about the phenomenology of the image has been present since Husserl's first texts. In this sense, the present article tries to show the intentional sense that the father of phenomenology grants to these concepts and, with this, to expose the flaws of the husserlian proposal, specifically, what Sartre will call the hylé of the image. filósofo francés denominará la hylé subjetiva de la imagen.

Palabras claves: Conciencia de imagen. Fantasía. Husserl. Imaginación. Sartre.

Keywords: Consciousness of image. Phantasy. Husserl. Imagination. Sartre. 
| Artigo | Edmund Husserl y Jean-Paul Sartre: apuntes sobre conciencia de imagen, fantasía e imaginación | | Sergio González Araneda |

\section{INTRODUCCIÓN}

La preocupación filosófica de Husserl respecto a la conciencia de imagen surge desde la necesidad de elaborar una teoría fenomenológica de los actos intuitivos, de los cuales destaca el acto imaginativo, aproximadamente desde la década de 1890. Durante los años 1904 y 1905 Husserl dicta el curso titulado Elementos de fenomenología y teoría del conocimiento, ${ }^{1}$ donde, en su tercera parte, centra su atención a la relación entre conciencia de imagen (Bildbewusstsein) y phantasie. A partir de este curso, se articula el marco más amplio desde el cual Husserl va a reflexionar acerca del tema. ${ }^{2}$ En efecto, desde este momento, la reflexión acerca de lo imaginativo se comprende según dos experiencias fenomenológicamente distintas. Por un lado, se constituye lo que comprende Husserl por conciencia de imagen, o la experiencia que cada individuo vivencia al observar una imagen (fotografía, cuadro de pintura, etc.). Por otro, Husserl añade a la problemática la idea de phantasie, entendiendo por ella aquella experiencia que no requiere de soporte material para vivenciar una imagen en la conciencia, porque, de hecho, estrictamente la phantasie no es vivencia de una imagen, a pesar de que sigue siendo un acto intencional.

De este modo, la articulación entre conciencia de imagen y phantasie entrega las herramientas necesarias para comprender el proyecto de una fenomenología de la imagen en Husserl. Esta cuestión es gravitante para nuestros objetivos, puesto que, la diferencia entre ambos conceptos (conciencia de imagen y phantasie) es significativamente radical, y Sartre, desde el pensamiento de Husserl, destaca el tratamiento común que se da a las imágenes

\footnotetext{
${ }^{1}$ En el semestre de invierno de 1904/05 Husserl imparte una lección titulada Problemas fundamentales del conocimiento cuyas tres primeras partes estaban dedicadas respectivamente a la percepción, a la atención y a la distinción entre los actos de fantasía y los actos de conciencia de imagen.

${ }^{2}$ Es importante no asumir que en el curso de 1904/05 se establece todo lo que Husserl va a pensar sobre el tema. Ocurren evoluciones muy importantes, hacia 1910 y 1912 y, luego, hacia 1917. Lo que el curso de 1904/05 sí aporta es la distinción entre conciencia de imagen y phantasie. Los detalles y características con que esta última será definida no se alcanzan hasta varios años más tarde.
} 
| Artigo | Edmund Husserl y Jean-Paul Sartre: apuntes sobre conciencia de imagen, fantasía e imaginación | | Sergio González Araneda |

pictóricas y las imágenes mentales, realizando breves referencias a Logische Untersuchungen e Ideen I, especialmente al final de L'Imagination.

Ahora bien, para llegar a este punto, es necesario revisar la estructura interna que sostiene lo que Husserl denomina conciencia de imagen, para poder diferenciar la particularidad de la phantasie. De este modo, advertir la diferencia fundamental entre el proyecto husserliano de una fenomenología de la imagen y lo que Sartre entenderá por conciencia de imagen, lo imaginario y su motor imaginativo.

\section{CONCIENCIA DE IMAGEN (BILDBEWUSSTSEIN) Y PHANTASIE EN HUSSERL}

Inicialmente Husserl entiende por conciencia de imagen toda experiencia de imágenes accesibles de modo senso-perceptivo, como lo es una fotografía, un cuadro de pintura o una escultura. Es decir, una imagen no es el representante mental de algo, sino que se comprende como un objeto trascendente que, inscrito en nuestra experiencia de mundo, nos ofrece un modo de intencionar y vivenciar trascendentemente algo (Husserl, 1980, p. 43).

Si la conciencia de imagen se constituye como conciencia que se dona su objeto por medio de una referencia perceptiva, entonces es un modo de intuición de menor grado que la percepción sensible. Dado que, mientras esta última experimenta intencionalmente el objeto en su presencia efectiva, la conciencia de imagen lo hace como referencia intencional a este en tanto tema apresente. Tomemos un ejemplo simple: cuando estoy frente a la biblioteca de mi habitación, la tengo presente en la totalidad de la experiencia efectiva, de modo que puedo contar y describir en orden cada uno de los libros, mientras que cuando la veo en una fotografía, solo lo hago parcialmente, pues la vivencio como imagen que se proyecta tenuemente en la conciencia. En rigor, como un objeto que ya no es la biblioteca. Husserl describe tempranamente esta situación en Logische Untersuchungen cuando señala:

Los actos intuitivos tienen plenitud, pero con diferencias graduales de más y de menos, dentro de la esfera de la imaginación. Pero la perfección de una imaginación, por grande que sea, presenta una diferencia frente a la percepción: no nos da el objeto mismo, ni siquiera en parte; nos da sólo su imagen, la cual, en cuanto que es imagen, no es nunca la cosa misma. Esta la tenemos en la percepción. La percepción "da" el objeto también con diversos grados de perfección, en diversos grados de "escorzo". El carácter intencional de la percepción consiste en presentar -en contraste con el mero re-presentar de la imaginación- (1999, p. 682). 
Husserl diferencia los rendimientos presentativos distinguiendo "entre la presentación (Gegenwärtigung) perceptiva y la presentificación (Vergegenwärtigung) imaginativa. En la conciencia de imagen, el objeto intencional aparece con sus elementos sensibles propios, pero no de manera íntegra” (Rubio, 2015, p. 95). Así, por ejemplo, la biblioteca fotografiada aparece con características propias, ya sean cromáticas $\mathrm{o}$ proporcionales que le resultan modificadoras, y que limitan nuestra experiencia de ella, por ejemplo, si emprendemos la misión de ver su reverso o la portada de un libro en particular, estamos condenados al fracaso.

Ahora bien, la conciencia de imagen, que posee una estructura compleja de articulación, tensiona los modos de orientarse intencionalmente dentro de su misma dinámica. A este respecto, es pertinente fijar la atención en el curso de invierno de 1904/05, pues allí Husserl distingue tres orientaciones intencionales que constituyen la experiencia de conciencia de imagen. En él, se distingue, en primer lugar, la imagen o soporte físico; en segundo lugar, el objeto representante o que reproduce en imagen; en tercer lugar, el objeto representado o reproducido vivencialmente en imagen (Husserl, 1980, p. 19).

Revisemos detalladamente esta última cuestión. La conciencia de imagen se constituye mediante una triplicidad de contenido y, por tanto, de aprehensión. Cuando, por ejemplo, observo una réplica de La pubertad cercana a las Pléyades de Max Ernst, el acto representativo y sus componentes significativos se articulan según tres objetos. En primer lugar, la imagen física (Bildding) que perceptivamente está presente, en este caso, una réplica de La pubertad cercana a las Pléyades colgada en la pared. Al igual que cualquier objeto perceptivo, el cuadro posee características que le otorgan una particularidad en su superficie: color, iluminación, tamaño, líneas, etc. En esta etapa, el objeto aún no es capturado como una imagen, pero representa el sustrato de la imagen.

En este punto, es necesario un nuevo tipo de aprehensión que, de cierta manera, reinterprete el contenido ya dado a un nivel perceptivo, en un sentido imaginativo. Los colores y las líneas ahora representan algo, en el sentido específico del término, lo que significa un aplazamiento, una indicación hacia una cosa otra trascendente. Este objeto es 
| Artigo | Edmund Husserl y Jean-Paul Sartre: apuntes sobre conciencia de imagen, fantasía e imaginación | | Sergio González Araneda |

precisamente lo que Husserl llama sujeto-imagen (Bildsubjekt) o, en este caso, el cuadro original de Ernst, puesto que "en la imaginación [...] el objeto no está presente en persona para la conciencia; él está presentificado, representado por medio de un contenido inmanente que es una 'imagen' o un 'analogon' de las cosas”' (Saraiva, 1970, p. 127).

Por tanto, comprendemos que para la fenomenología husserliana la conciencia de imagen consiste en la articulación de tres orientaciones intencionales, que, a su vez, poseen cada una de ellas su respectivo correlato, a saber: las orientaciones hacia la cosa-imagen (Bildding), el objeto-imagen (Bildobjekt) y el sujeto-imagen (Bildsubjekt). Así, la captación perceptiva de la tela coloreada, considerada por sí sola, aisladamente, es un acto de percepción. Pero, cuando está puesta al servicio de la captación de algo que no está allí en persona, una mujer desnuda, por ejemplo, forma parte de una experiencia compleja que no se agota en la percepción sensible. ${ }^{3}$

En este contexto, la conciencia de imagen queda definida por medio de una peculiaridad esencial, y es que, al operar, la conciencia de imagen aprehende más de aquello dado perceptivamente, como presencia efectiva. Para explicar esta peculiaridad, Husserl describe la conciencia de imagen como tensión de intencionalidades. Consiste, por un lado, en una intencionalidad dirigida hacia la cosa-imagen y la intencionalidad dirigida al objetoimagen; por otro, una intencionalidad dirigida al sujeto-imagen o tema de la imagen (Husserl,

\footnotetext{
${ }^{3}$ Marc Richir escribe a este respecto: "Es como si, a través del cuadro, percibiese la cosa a pesar de no estar esta ahí, en carne y hueso. Así pues, el cuadro realmente percibido, el que se encuentra ahí en carne y hueso, comporta lo que Husserl denomina Bildobjekt, y que es un fictum, una ilusión (Schein) perceptiva; ilusión que, sin embargo, alberga el carácter irreductiblemente paradójico de no estar llamada a evaporarse definitivamente como ilusión en el curso de la experiencia en beneficio de una "verdadera" percepción (la de un objeto en carne y hueso), sino que conduce, por el contrario, y en virtud de su propio funcionamiento, a la cuasi-percepción de lo representado como irreductiblemente no-presente, y eso es lo que Husserl denomina Bildsubjekt. He ahí pues el intrincado carácter de la imagen: el de ser un fictum que re-presenta, que hace o vuelve presente (Vergegenwärtigung) algo como ausente. El Bildsubjekt se vuelve pues presente en el acto de cuasi-percepción; sin embargo, permanece, como tal, no-presente, ya que por muy presente que se haga en la imagen, no es él mismo quien está ahí, en carne y hueso" (2012, pp. 335-336).
} 
| Artigo | Edmund Husserl y Jean-Paul Sartre: apuntes sobre conciencia de imagen, fantasía e imaginación | | Sergio González Araneda |

1999, pp. 527-529). En efecto, la captación de la biblioteca en una fotografía hace presente a la biblioteca misma, ubicada en una determinada posición de mi habitación, y no al papel fotográfico o la tinta que posee dicha fotografía. En este sentido, el hacer presente se efectúa en imagen y no en persona.

Como vemos, existe una tesis fundamental en la fenomenología según la cual la conciencia de imagen está fundada en la percepción sensible. ${ }^{4}$ Sin embargo, esta no pretende afirmar que "vemos" imágenes, en una operación semejante a la percepción visual. El criterio fenomenológico para conectar la experiencia de imagen con la percepción sensible es la plenitud intuitiva, es decir, el grado de presencia con que el objeto intencional aparece. ${ }^{5}$ Así como en la percepción sensible aparece el objeto mismo, en la experiencia de imagen aparece el objeto con un nivel inferior de presencia, puesto que:

La cosa espacial que vemos es con toda su trascendencia algo percibido, algo dado en su propia persona a la conciencia. No se da en lugar de ella una imagen o un signo. No se subrogue al percibir la conciencia del signo o de la imagen. Entre percepción de una parte, y representación simbólica por medio de una imagen o simbólica por medio de un signo, de otra parte, hay una infranqueable diferencia esencial. En estas formas de representación intuimos algo con la conciencia de que es imagen o signo indicador de otra cosa: teniendo en el campo de la intuición lo

\footnotetext{
${ }^{4}$ A este respecto, se tornan sumamente lúcidas las palabras de María Manuela Saraiva: "La adecuación de la percepción a su objeto es siempre más perfecta que la adecuación de un acto de la imaginación, dado que la plenificación perceptiva se hace por los contenidos que presentan o exponen al objeto mismo, mientras que la plenificación imaginativa se efectúa a través de contenidos que no son más que simples imágenes: los fantasmas" (Saraiva, 1970, p. 130).

${ }^{5}$ A partir de las reflexiones en torno a la conciencia de imagen estética y la conciencia de imagen no estética, Hans Reiner Sepp vislumbra el principal descubrimiento de Husserl respecto de la relación entre acto intencional de imaginación y aprehensión intencional percepctiva: "En mi opinión, la única transformación decisiva en los análisis husserlianos de la conciencia de imagen consiste en que, más tarde, Husserl vio con más claridad en la percepción del objeto de la imagen un efecto de la imaginación que modifica la percepción de la cosa y, al mismo tiempo, fundió más íntimamente ambas operaciones de aprehensión -percepción del soporte físico e imaginación modificante-, en la operación unitaria de la conciencia de imagen que definió como 'percepción sin creencia'. Pese a todo, siguió siendo dominante la orientación fundamental hacia la percepción" (Sepp, 1998, p. 155).
} 
| Artigo | Edmund Husserl y Jean-Paul Sartre: apuntes sobre conciencia de imagen, fantasía e imaginación | | Sergio González Araneda |

uno, no nos dirigimos a ello, sino, por el intermedio de un apercibir fundado, a lo otro, lo reproducido por la imagen o indicado por el signo. En la percepción no se puede hablar de nada semejante, como tampoco en el simple recuerdo o la simple fantasía (Husserl, 1962, p. 98).

Si bien el objeto-imagen (Bildobjekt) solamente nos aparece gracias a que primero percibimos un objeto físico, una cosa-imagen (Bildding) en el mundo, este -Bildobjekt - no se reduce ni a sus bases materiales, ni a las figuras reales que están plasmadas en, por ejemplo, un cuadro o una fotografía, por más que todo esto sea condición necesaria de la aparición del objeto-imagen. El objeto-imagen es aparente respecto de cualquier "posición" en el mundo, y su función esencial consiste en representar una presencia intencional (Bildsubjekt), difiriendo esencialmente, aunque lo ilustre mediante ciertas semejanzas significativas. ${ }^{6}$

De hecho el objeto-imagen no podría ejercer de ninguna manera su función de imagen de un cierto objeto-otro si no mostrara la siguiente diferencia crucial: por un lado, respecto de su soporte material y de los trazos reales que forman una figura real sobre el lienzo o el papel, y, por otro, respecto de lo imaginado temáticamente. Volvamos al ejemplo propuesto por Husserl para aclarar esta dinámica. El objeto-imagen no es la cosa física que cuelga de la pared. Al respecto escribe Husserl:

La fotografía como cosa es un objeto real y como tal es aceptada en la percepción. Pero esa imagen [el objeto-imagen] es algo aparente que nunca ha existido y nunca existirá, que en ningún momento validamos como realidad. Así pues, distinguimos la imagen física de la imagen representante, del objeto aparente que tiene la función de reproducir imaginativamente, y por el cual es reproducido el tema de la imagen (Husserl, 1980, p. 19).

Ahora bien, de momento, hemos de comprender la conciencia de imagen husserliana ligada a un soporte físico, perceptivo, que actúa como fundamento de esta conciencia en cuanto objeto-imagen. Sin embargo, el análisis que brinda Husserl, respecto a los actos

\footnotetext{
6 "El objeto que, propiamente hablando, es traído a aparición en todo ello (el Bildobjekt) es, en efecto, el que funge como enlace de las otras dos objetividades y el que con justeza ha de recibir el nombre de imagen: en él, cuya constitución es posible sólo gracias al contenido sensible de la aprehensión que corresponde a la imagen física, el observador ve, o mejor, intuye, el tema de la imagen" (Chávez, 2016, p. 71).
} 
| Artigo | Edmund Husserl y Jean-Paul Sartre: apuntes sobre conciencia de imagen, fantasía e imaginación | | Sergio González Araneda |

intuitivos de la imaginación no se agota allí. Por el contrario, así como la conciencia de imagen opera siguiendo la tesis de lo no presente intencionado según un soporte sensoperceptivo, ocurre que existen experiencias donde no es posible hallar soporte perceptivo alguno, es decir, experiencias donde la imaginación opera por medio de lo no presente en tanto phantasie. ${ }^{7}$

La phantasie tiene por característica básica el no poseer Bildobjekt, por ende, no posee imagen, en el sentido de un soporte físico como referencia. Al menos esto de un modo general, puesto que, cuando pretendo representarme algo no presente, efectivamente intenciono y compongo una imagen que es producto de recuerdos, influjos de memoria o bien de otras imágenes. No obstante, esta imagen no opera del mismo modo que la conciencia de imagen, es decir, a partir de un soporte perceptivo (Bildding) como acabamos de ver, sino que:

Es, ella misma, un Bildobjekt, sólo que imaginado o 'imaginativo' (imaginario) y carente de presencia perceptiva: por ejemplo cuando trato de imaginarme a Julio César (caso del que, claro está, no existen recuerdos, sino, a lo sumo, recuerdos de imágenes, de Bildobjekt determinados) (Richir, 2012, p. 337).

Ahora, si no hay Bildobjekt en la phantasie, se debe a que esta experiencia, al igual que la percepción, apercibe directamente sus objetos a través de sus apariciones, en este caso, apariciones de phantasie (Phantasieerscheinungen). ${ }^{8}$ Sucede entonces que, a pesar de que no existe representación presente de orden perceptiva, existen apariciones producidas por elementos que no están presentes, como sí lo están durante la experiencia perceptiva, de allí que la phantasie se comprenda como experiencia re-productiva. En este contexto, el punto

\footnotetext{
${ }^{7}$ La postura de Marc Richir es radical sobre la composición de la imaginación husserliana: "la fenomenología husserliana de la imaginación, [...] se completa con una fenomenología de la phantasie" (2011, p. 33).

${ }^{8}$ Vale la pena señalar que Husserl comenzó por interpretar la Phantasie como una variante de la conciencia de imagen. Se evidencia en sus conferencias de 1905. La tesis de que la Phantasie no es la conciencia de imagen (Bildbewusstsein) sino la reproducción (Reproduktion) fue descubierta en el desarrollo mismo de las conferencias.
} 
| Artigo | Edmund Husserl y Jean-Paul Sartre: apuntes sobre conciencia de imagen, fantasía e imaginación | | Sergio González Araneda |

crucial que despierta en Sartre una mirada crítica sobre la obra de Husserl es en relación al modo en que se comprende y existe la aparición de lo no presente.

La phantasie, por tanto, posee intrínsecamente un sentido oscuro, brumoso y pobre, pues no solo se encuentra desprovista de presencia efectiva, sino que adquiere un carácter principalmente huidizo y fluctuante al ponerse por sí misma como presencia intencional significativa. Dicho de otro modo, la phantasie no cuenta con el proceso intencional característico de la conciencia de imagen (Bildbewusstsein), pues es pura aparición reproductiva. ${ }^{9}$ Estas características de la phantasie son descritas del siguiente modo por Husserl:

En la phantasie no tenemos "presente" y, por lo tanto, tampoco Bildobjekt alguno. En la phantasie clara [scil. casos en que las apariciones son claras], vivimos phantasmas [scil. phantasmata] y aprehensiones [Auffassungen] presentificantes que no constituyen nada que se tenga ahí, en presente, y que, por lo tanto, hubiera entonces de funcionar, en primer término, como portador de una conciencia de imagen. La referencia al presente está radicalmente ausente de la propia aparición. De modo inmediato acontece un ver (Schauen) lo mentado en el seno de lo que aparece. Podemos ejecutar la aprehensión posteriormente: he aquí ahora, y por lo pronto, lo que me aparece; tengo ahora esta aparición del edificio del ayuntamiento, etc., $\mathrm{y}$, a través de dicha aparición, me remito al edificio del ayuntamiento "en persona". Sin embargo, en la vivencia simple de phantasie no se efectúa la aprehensión de una "aparición presente del edificio del ayuntamiento", la aprehensión de un Bildobjekt presentándose dentro del presente (Husserl, 1980, p. 79).

En el caso de la conciencia de imagen, a diferencia de la experiencia perceptiva, el objeto-imagen es constituido como carente de realidad. Esta peculiar modalidad con la que aparece el objeto-imagen se debe al contraste producido entre la aprehensión perceptiva y la aprehensión imaginativa, lo que, en definitiva, distingue lo aparente de lo real. En este sentido, la aprehensión de una imagen no se limita a ser simple percepción de un objeto trascendente, es siempre algo más, es, en efecto, imaginación que desborda temáticamente lo aprehendido. En el caso puntual de la phantasie, no existe captación de imagen, por lo que adquiere características sumamente particulares y delicadas que la diferencian de la

\footnotetext{
${ }^{9}$ Marc Richir ha contribuido enormemente para despejar este tipo de problemas. Siguiendo a Husserl, Richir sostiene que la imaginación, en tanto intencionalidad objetiva, es presentificación de lo presente, mientras que la fantasía es presentación de lo no presente (Richir, 2000, p. 260), como sería el caso de la imagen de un centauro tocando la flauta.
} 
| Artigo | Edmund Husserl y Jean-Paul Sartre: apuntes sobre conciencia de imagen, fantasía e imaginación | | Sergio González Araneda |

conciencia de imagen, y que, por tanto, la asimilan a la tradición de una fenomenología de lo irreal (Fink) o una fenomenología de la imaginación sin imágenes (Richir o Bachelard). ${ }^{10}$

La intencionalidad imaginativa que opera en la phantasie no consiste en "representarse en la mente" un objeto-imagen (Bildobjekt) que se supone presente en lugar de un sujeto-imagen (Bildsubjekt) ausente. ${ }^{11}$ En efecto, resulta que dicho objeto-imagen, no solo no se encuentra presente, sino que no existe, no es tematizado en tanto la phantasie no comporta una imagen. Es, pues, una intención inmediatamente irreal mentada gracias a la imaginación, en el caso de Husserl, re-productora. Antes de que Husserl, al final del curso de 1904/05, haga la separación entre conciencia de imagen y phantasie, entrega la siguiente definición:

En la phantasie aparece el objeto mismo, justamente, en tanto que él es lo que ahí aparece, pero no aparece como presente. Él está solamente presentificado, es casi como si estuviera ahí, pero solo casi: él se nos aparece en imagen. Los latinos dicen imaginatio (Husserl, 1980, p. 16).

Hasta este punto, comprendemos que según Husserl la conciencia intencional tanto desde la conciencia de imagen (Bildbewusstsein) como desde la phantasie posee dos fundamentos. El primero de ellos dice relación con la función transformadora del mundo, expresada como liberación de la conciencia respecto de la realidad presente al referir intencionalmente a este en su ausencia y desbordarlo como tema de la imagen. El segundo aspecto, ligado al primero, es el hecho que la imaginación sobrepasa la sensibilidad

\footnotetext{
${ }^{10}$ De las complejas características que constituyen la phantasie resalta el oscuro problema acerca de la hylé de la phantasie y las posteriores derivas acerca de los "fantasmata".

11 "Será pues en la intención que mienta el objeto, intención propia de la apercepción de phantasie, donde pueda anclarse (sin que ello haya de producirse necesariamente) la intención imaginativa como intención que mienta y aprehende inmediatamente la semejanza (es ahí donde se insinúa la conciencia de imagen) entre la aparición de phantasie y el objeto del que es esta aparición" (Richir, 2012, p. 344).
} 
| Artigo | Edmund Husserl y Jean-Paul Sartre: apuntes sobre conciencia de imagen, fantasía e imaginación | | Sergio González Araneda |

perceptiva, superando, de este modo, la aprehensión de lo real. Es decir, la imaginación está ligada esencialmente a la formación de imágenes no presentes en tanto tema de imágenes. ${ }^{12}$

Decidir, la referencia a la existencia o inexistencia de un objeto (o mejor, si el objeto se aprehende como existente o no) es una modalidad particular de la aprehensión que Husserl llama, siguiendo a Hume, carácter de creencia o posicionalidad (Stellungnahme). La teoría de la posicionalidad intencional encuentra sus raíces en la concepción de intencionalidad desarrollada por Husserl en Logische Untersuchungen. Desde allí, la crítica de Sartre considerará tres modos posicionales, a saber: el objeto se coloca como realmente existente, como inexistente o no se coloca en absoluto. Las dos primeras actitudes tienen en común el hecho de tomar una posición con respecto al ser o no ser del objeto intencional. El último, que Husserl llamará en Ideen I modificación de neutralidad, se caracteriza por el hecho de abstenerse de cualquier tipo de posición presente o ausente.

En la conciencia neutral el momento posicional no se traduce en realidad, por lo tanto se inhibe. Esta inhibición desempeña un papel fundamental en la comprensión de lo que Husserl llama conciencia imaginativa, pues esta se pone en juego al momento de la captura de un soporte perceptivo (pinturas, esculturas, representaciones teatrales). Por lo tanto, el perceptio constituye una percepción desprovista del momento de creencia y describe con precisión esa experiencia por la cual, al observar a las personas que realizan gestos e imitaciones en un escenario, somos proyectados directamente al fantástico mundo que

\footnotetext{
${ }^{12}$ En el Anexo LIX del tomo XXIII de Husserliana, Husserl esboza una teoría del arte a partir de la distinción que existen entre conciencia de imagen y phantasie. Allí se tensiona el fundamento de la percepción como experiencia dada por medio de un ahora actual, en relación con el fundamento que ofrece la imaginación, en tanto ausencia figurativa. Allí sostiene: "Todo arte se mueve entre esos dos extremos. A) Arte-imagen: representador en imagen, figurativo, propiciado por la conciencia de imagen. B) Arte puramente fantástico, productor de formaciones de fantasía en mera modificación de neutralidad. Por lo menos no productor de imaginería concreta alguna. El 'érase una vez' aún está relacionado con el ahora actual y el mundo, y el conflicto con él puede indicar una imaginería que, no obstante, no constituye un objeto-imagen visible. Música. Fantasía lúdica" (Husserl, 2016, p. 183).
} 
| Artigo | Edmund Husserl y Jean-Paul Sartre: apuntes sobre conciencia de imagen, fantasía e imaginación | | Sergio González Araneda |

representan. Por esto, es necesario comprenderla como una percepción en el sentido de Perzeption y no como Wahrnehmung.

Por otro lado, el concepto de posicionalidad necesita un análisis aún más profundo y fundamental. La motivación para esto se encuentra en su comprensión de ese tipo de posición inherente a las experiencias de phantasie. En este caso, como ya se mencionó, no existe un sustrato que motive y apoye la experiencia imaginativa como sucede con la conciencia de la imagen. De hecho, no podríamos hablar aquí de un cambio en la neutralidad, ya que no existe una posición de ser o no ser que requiera ser modificada y, por tanto, inhibida. ${ }^{13}$

Si realmente no fueran nada, no entenderíamos el motivo por el cual es posible hablar de mundos fantásticos como los de cuentos de hadas, literatura o teatro, mundos que exhiben validez en un nivel intersubjetivo y, por lo tanto, no son resultado o producto de la mente de un individuo aislado. En este sentido, podemos vislumbrar en los manuscritos de Husserl posteriores a 1904/05, una noción de posicionalidad que lo lleva a postular la existencia de un cuarto modo posicional además de los tres ya mencionados. Esta es la cuasiposicionalidad del como-si (als-ob) que no puede entenderse como una mera modificación de la neutralidad, puesto que está a cargo de una posición de autonomía por sí misma. ${ }^{14}$

Si analizamos el ejemplo husserliano del centauro tocando flauta (como se verá, criticado por Sartre), es evidente que no hay posición alguna en el sentido estricto. El acto imaginativo que experimento al vivenciar un centauro tocando flauta, no produce que este exista, ni que sea negado. Se podría decir que mi actitud es neutral respecto a la posición de ser del objeto imaginado. Sin embargo, esto no es del todo correcto, ya que la modificación

\footnotetext{
${ }^{13}$ No obstante, esto no resulta ser del todo exacto. Husserl presenta la neutralidad como una modificación. Sin embargo, una conciencia neutra modificada puede presentarse desde un comienzo, sin ser una modificación de una conciencia posicional previa. La ficción, la narración de historias son casos evidentes de una conciencia neutral sin una conciencia posicional previa.

${ }^{14}$ Esta corresponde a la conciencia de neutralidad completamente desarrollada por Husserl. Ver, por ejemplo, la tercera sección de Analyses concerning passive and active synthesis, donde Husserl desarrolla su teoría de la ficción.
} 
| Artigo | Edmund Husserl y Jean-Paul Sartre: apuntes sobre conciencia de imagen, fantasía e imaginación | | Sergio González Araneda |

de la neutralidad implica que, al comienzo de mi fantaseo, en realidad he desempeñado una posición de ser o no ser, en este caso, del centauro que toca flauta. ${ }^{15}$

Este último punto resulta decisivo para la tradición fenomenológica ligada al estudio de la imaginación. Desde luego, la tradición francesa hace eco de ello y, tanto Bachelard como Sartre tomarán distancia de la tesis husserliana sobre la imaginación como motor formador de imágenes. Ambos filósofos, lectores críticos tanto de Husserl como de Bergson, identifican la función de la imaginación antes que todo como "facultad de deformar las imágenes suministradas por la percepción y, sobre todo, la facultad de librarnos de las imágenes primeras, de cambiar las imágenes” (Bachelard, 2012, p. 9).

En este contexto no puede existir acción imaginante sin modificación o cambio de imágenes, puesto que "percibir e imaginar son antitéticos como presencia y ausencia [en efecto] Imaginar es ausentarse, es lanzarse hacia una vida nueva" (Bachelard, 2012, p. 12). Es decir, la acción imaginante está investida de una función re-significante de la realidad, que no requiere de un soporte físico perceptivo, pero que tampoco es formación y reproducción de imágenes apercibidas directamente. En esta ocasión, la imaginación alcanza un nivel liberador al constituirse como pura irrealidad deformadora e irruptora en lo presente.

\section{CRITICA DE SARTRE A LA CONCIENCIA DE IMAGEN (BILDBEWUSSTSEIN) HUSSERLIANA}

Es necesario destacar que el registro de las obras de Husserl en la producción sartreana se limita a sus principales textos publicados en vida: Logische Untersuchungen I y II, Ideen I, Vorlesungen zur Phänomenologie des inneren Zeitbewusstseins, Formale und Transzendentale Logik y Cartesianische Meditationen. A diferencia, por ejemplo, de

\footnotetext{
${ }^{15}$ A este respecto, valga señalar que "para la conciencia de imagen se requiere la percepción, luego una modificación de la percepción en la neutralidad y finalmente la irrupción de la imaginación y el juego en la libre fantasía" (Chávez, 2016, p. 77)
} 
| Artigo | Edmund Husserl y Jean-Paul Sartre: apuntes sobre conciencia de imagen, fantasía e imaginación | | Sergio González Araneda |

Merleau-Ponty, ${ }^{16}$ Sartre no da señales de haber estudiado los textos inéditos de Husserl (considerando Husserliana XXIII), a pesar de que sí hay indicios que muestran su conocimiento sobre la existencia de tales obras. En L'imagination (1936) refiriéndose al problema husserliano de la modificación de neutralidad que emparejaría a la imagen con la percepción, Sartre sostiene: “Tales son las breves alusiones que Husserl hace a una teoría que ha precisado sin duda en sus cursos y en sus obras inéditas, pero que en las Ideen es aún muy fragmentaria” (1984, p. 189). Sin embargo, no vuelve a pronunciarse al respecto.

Consecuentemente, el conocimiento que Sartre posee del proyecto fenomenológico husserliano es sumamente parcial y limitado. Por ello, revisaremos las principales críticas que Sartre enuncia sobre la fenomenología husserliana, centrándose en la etapa estática del proyecto fenomenológico de Husserl. De hecho, cada vez que Sartre refiere críticamente a la teoría de la imagen de Husserl, lo hace refiriendo a los textos señalados, lo que resulta un enorme problema filosófico y metodológico. Puesto que, precisamente es en Husserliana XXIII donde se encuentra sistematizada de manera más completa y precisa todo aquello que Husserl entenderá por constitución de imagen. En otras palabras, el conocimiento que Sartre posee de la teoría de la imagen de Husserl es, a lo menos, incompleto y parcial limitándose a la etapa estática de Husserl y dejando a un lado el motor que anima la teorización husserliana, esto es, la constitución de una fenomenología genética (De Coorebyter, 2012).

La tesis crucial que está en juego, a juicio de Sartre, es sobre el carácter intencional de la imaginación. Cuando se trata de una imaginación con soporte físico, por ejemplo, cuando hacemos uso perceptivo de un busto para representarnos a Platón, no cabe duda sobre la naturaleza intencional del acto imaginante: el busto percibido que sirve de analogon es externo a la conciencia, en este caso, el busto de Platón. Pero, como hemos señalado, sucedería lo mismo cuando el analogon es puramente mental o psíquico. La imagen que puedo formar de un pájaro en su ausencia no es un duplicado del pájaro que existe, ni un retrato, ni una pintura de él que estaría, de algún modo, oculta en mi conciencia y que contemplaría por sí mismo; mediante su analogon, apunto el pájaro en pleno vuelo. Al igual

${ }^{16}$ Maurice Merleau-Ponty tuvo acceso a textos inéditos de Husserl durante su visita al Archives-Husserl de Louvain en 1939. 
| Artigo | Edmund Husserl y Jean-Paul Sartre: apuntes sobre conciencia de imagen, fantasía e imaginación | | Sergio González Araneda |

como lo hace la imagen física, la imagen mental me envía fuera de mí, al núcleo mismo de las cosas. Por tanto, la expresión simplista de imágenes internas, en contraposición a los objetos externos, no puede ser tolerada en el suelo de la fenomenología (Husserl, 1999, pp. 611-612).

El carácter intencional de la imaginación es aún más fundamental para la constitución de lo irreal. Sartre, en el cuarto capítulo de L'Imagination, vuelve a la respuesta entregada por Husserl a la tradición mentalista e idealista. Allí se pregunta si acaso el centauro tocando flauta que imaginamos ¿no es una libre colección de representaciones en nosotros? A este cuestionamiento, Husserl responde que, desde luego, el centauro es una invención pura de la mente, pero no está presente en la conciencia, pues:

El centauro mismo no es naturalmente nada psíquico, no existe ni en el alma ni en la conciencia ni en ninguna parte; no existe de ninguna manera, es total invención. Para ser más exacto: el estado de conciencia de invención es invención de ese centauro (Sartre, 1984, p. 185).

En esta línea, Sartre expone el error del psicologismo que reduce a simples formaciones mentales o psíquicas la no-existencia del centauro. Sin embargo, precisamente porque el centauro es un ser ficticio, es que no es un contenido psíquico. Recordemos las palabras de Sartre:

Sin duda, hay ahí, con motivo de estos inexistentes, formaciones psíquicas reales; y se comprende el error del psicologismo: grande era la tentación de abandonar estos seres míticos a su nada y de no tomar en cuenta sino contenidos psíquicos. Pero, precisamente, Husserl restituye al centauro su trascendencia en el seno mismo de su nada. Nada, cuanto se quiera: pero por eso mismo no está en la conciencia (1984, p. 186).

En este estado de cosas, la intencionalidad de la imaginación equivale a afirmar que la imaginación y la percepción son paralelas, pero con un abismo en medio de ellas (Mori, 2012, p. 12). El paralelismo entre imaginación y percepción corresponde a la primera de las cuatro características fundamentales de la imagen detallada en el primer capítulo de L'Imaginaire. ${ }^{17}$ La percepción y la imaginación son dos formas diferentes de apuntar y donarse un mismo objeto, dos actos que son estricta y rigurosamente intencionales. Si apunto

${ }^{17}$ Esta primera parte titulada "Lo cierto" deriva de Structure intentionnelle de l'image, ensayo publicado en Revue de Métaphysique et de Morale en octubre de 1938. 
| Artigo | Edmund Husserl y Jean-Paul Sartre: apuntes sobre conciencia de imagen, fantasía e imaginación | | Sergio González Araneda |

a mi amigo Pedro en su ausencia, escribe Sartre, "la conciencia imaginante que tengo de Pedro no es conciencia de la imagen de Pedro: Pedro está alcanzado directamente, mi atención no está dirigida a una imagen, sino en un objeto” (2005, p. 16).

Ahora bien, podemos observar con plenitud que, en el caso donde el objeto imaginado es irreal, la intencionalidad de la imagen no está amenazada, sino que, por el contrario, se lleva al extremo. La imaginación, por lo tanto, siempre requiere un analogon, ya sea mental o físico, pero, a diferencia de la percepción, puede prescindir de la presencia real del objeto hasta el punto de que, como hemos visto, su objeto puede ser puramente ficticio (Leiva, 2016). En otras palabras, imaginación, a diferencia de la percepción se define como la constitución significativa de un ser ausente, inexistente o existente en otro lugar. Es decir, de un objeto planteado como una nada, que es precisamente la tercera característica de la conciencia imaginante.

Sartre comienza L'Imaginaire, con el objetivo de profundizar y sistematizar la postura respecto de Husserl (específicamente de Ideen I) expuesta en L'Imagination. Por ello, lo primero que salta a la vista es que la imagen posee una estructura intencional y, por tanto, no se constituye, contrariamente a la psicología tradicional y a la tradición bergsoniana, ${ }^{18}$ ni como un pensamiento confuso, ni un sentimiento debilitado, ni una cosa. En este sentido, la imagen no es un contenido inerte de o en la conciencia, 19 "es una manera determinada que tiene el objeto de aparecer a la conciencia, o, si se prefiere, una determinada manera que tiene la conciencia de darse un objeto" (2005, pp. 15-16).

Llegados a este punto, es necesario volver a L'Imagination para retomar las dos consideraciones que, a juicio de Sartre, Husserl no habría podido dar respuesta. Allí se plantea, por un lado, que la filosofía fenomenológica de Husserl carece de una descripción de esencias que permita comprender a ciencia cierta "qué tipo de naturaleza es la intención

\footnotetext{
${ }^{18}$ Véase la segunda y tercera parte de L'Imagination tituladas "El problema de la imagen e intentos de los psicólogos de descubrir un método positivo" y "Las contradicciones de la concepción clásica" respectivamente. 19 "La imagen es un acto y no una cosa. La imagen es conciencia de algo" (Sartre, 1984, p. 202). Valdría señalar que para Husserl la imagen no es conciencia a la manera en que la está entendiendo Sartre, sino el correlato del acto de imaginar, que en Sartre será lo imaginario.
} 
| Artigo | Edmund Husserl y Jean-Paul Sartre: apuntes sobre conciencia de imagen, fantasía e imaginación | | Sergio González Araneda |

de la imagen y cómo difiere de la percepción". Por otro lado, Husserl no habría entregado solución alguna al problema sobre el material de la imagen mental (1984, pp. 187-188). Efectivamente, los dos puntos son decisivos para el proyecto de una fenomenología de la imagen y para la constitución y despliegue de lo imaginario, puesto que, mientras la primera consideración apunta a la intención imaginativa, la segunda lo hace respecto de la estructura de la imagen mental.

En este contexto, la crítica sartreana surge del análisis sobre el modo en que la percepción es posible en este marco de trascendencia. Señala, por tanto, que los elementos subjetivos inmanentes son una "materia subjetiva, la hylé sobre la cual se aplica la intención que se trasciende y procura atrapar al [objeto] rojo de afuera" (1984, p. 184). Con esto, el objeto permanece exterior a la conciencia por naturaleza. Sin embargo, existen cualidades que lo perfilan (Abschattungen) en la medida que constituyen "una impresión subjetiva que, sin duda, es 'análoga' al rojo [o a la forma] del objeto" (1984, p. 184), pero sin serlo en definitiva.

La impresión subjetiva es análoga a la cualidad constituyente del objeto, esto se debe a que la intencionalidad opera sobre una hylé subjetiva. Dicho de otra forma, la intencionalidad opera sobre un elemento que es subjetivo, pero que aún no es intencional. De modo que, al igual que en la experiencia perceptiva, en la imaginación Husserl distingue "una intención imaginante y una 'hylé' [subjetiva] que la intención viene a 'animar' (Sartre, 1984, p. 185). ${ }^{20}$ La dinámica entre el contenido hylético y el movimiento intencional significante es lo que anima la vida psíquica en la dinámica, afirma Sartre, denominada nóesis y noema.

En definitiva, la distinción entre imagen mental e imagen material está fundada en la materia sobre la cual es ejecutada la síntesis imaginante, una hylé mental, subjetiva para la imagen mental y la materialidad de los objetos (cuadros, bustos, etc.) en la imagen material que, sin ser el objeto exterior mismo (la cosa-imagen como veíamos) sí es de algún modo análoga a él. Por esto, Sartre sostiene la necesidad de un estudio sobre la hylé propia de la imagen mental, la materia de la imagen y el sentido que tiene en razón de la intención que la

20 "La hylé, naturalmente, sigue siendo subjetiva; pero, al mismo tiempo, el objeto de la imagen, separado del puro 'contenido' se planta fuera de la conciencia como algo radicalmente diferente" (Sartre, 1984, p. 185). 
| Artigo | Edmund Husserl y Jean-Paul Sartre: apuntes sobre conciencia de imagen, fantasía e imaginación | | Sergio González Araneda |

posibilita. No obstante, admite que la hylé es problemática cuando es definida como pasividad en el acto imaginativo, pues reconduce todo análisis a la ilusión de inmanencia que caracteriza al idealismo. Así, en el caso de admitir una hylé en la imagen mental, esta debe ser necesariamente activa: ${ }^{21}$

La distinción entre imagen mental y percepción no podría provenir únicamente de la intencionalidad: es necesario pero no suficiente que las intenciones difieran. Es necesario también que las materias sean distintas. Tal vez incluso sea necesario que la materia de la imagen sea ella misma espontaneidad, pero una espontaneidad de tipo inferior (Sartre, 1984, p. 198).

Lo fundamental en la crítica sartreana a la propuesta husserliana, apunta a la constitución de una materia activa, opuesta a la materia pasiva de la percepción en Husserl, que, junto con evitar una concepción idealista de la imagen, abra el camino para una configuración radical sobre la imaginación en clave creativa y estética. Es decir, la materia activa de la imagen se presenta como suelo operacional de lo que Sartre denominará como lo imaginario.

El interés sartreano por fundamentar una teoría de la imagen y de la imaginación en clave creadora, estética y espontánea se materializa con la constitución de lo imaginario en su obra homónima. La descripción formal-analítica del analogon y la pregunta por la hylé de la imagen mental dan lugar a las investigaciones sobre la función analógica de la conciencia, de sus modalidades operacionales y sus consecuencias de orden ontológico y estético.

Lo imaginario se constituye desde la tesis donde el objeto imaginado es un ser dadoausente, ya que el objeto es dado a la conciencia como aquello que no está en el mundo. Así, los objetos de percepción y los objetos de imaginación tienen existencias radicalmente diferentes: los del primer tipo real y los del segundo irreal. Por ello lo que caracteriza al acto imaginante es un principio de negación (Sartre, 2005, p. 253), donde lo negado es precisamente la realidad-dada-presente y, en su lugar, se presentifica (presentificándolo como nada dirá Sartre) un nuevo sentido, por tanto "el acto imaginativo es así a la vez constituyente, aislante y aniquilador" (2005, p. 250).

${ }^{21}$ Es justo señalar que Husserl dedicó importantes esfuerzos para distinguir entre sensaciones y fantasmas, como hyle propio de las percepciones y fantasías. 
| Artigo | Edmund Husserl y Jean-Paul Sartre: apuntes sobre conciencia de imagen, fantasía e imaginación | | Sergio González Araneda |

En este contexto, comprendemos que para Sartre el modo en que un objeto se dona perceptivamente es radicalmente distinto al modo en que es donado como imaginario. Para el primero, Sartre continúa el análisis husserliano donde la "percepción es el acto por el cual la conciencia se pone en presencia de un objeto tempo-espacial" (2005, p. 169), mientras que para el segundo, se produce un des-anclaje fundamental del mundo en clave creativa, que, no obstante, supone la distancia husserliana entre lo imaginado y lo presente. Veámoslo en detalle. Tomemos el extenso y clásico ejercicio mental de Alain, donde se manifiesta la tensión entre el objeto imaginado, el objeto percibido y sus implicancias en el modo de conocerlo que hay en medio de ambos. Alain sostiene:

\begin{abstract}
Muchos tienen, como dicen, en su memoria, la imagen del Panteón, y, según creen, pueden hacerla aparecer de nuevo sin mayores problemas. Les pediría yo entonces, si bien les parece, que contasen las columnas que sostienen la parte frontal; pues bien, resultará que no sólo no podrán contarlas, sino que no podrán siquiera intentarlo. Y, sin embargo, esta operación es la más fácil del mundo tan pronto como uno tiene el Panteón ante sus ojos. ¿Qué es entonces lo que ven cuando imaginan el Panteón? ¿Acaso ven algo? En lo que a mí respecta, cuando me planteo a mí mismo esa misma pregunta, no puedo decir que vea algo semejante al Panteón. Formo, según me parece, la imagen de una columna, de un capitel, de una porción de muro; sin embargo, como no puedo en absoluto fijar esas imágenes al modo en que, por el contrario, sí lo puedo la mirada por así decirlo directa, que me sitúa de inmediato en presencia de los objetos que tengo ante los ojos; así pues, nada puedo decir de dichas imágenes si no es que me pareció haberlas apercibido apenas un instante (1963, p. 345).
\end{abstract}

Alain llega la conclusión que la imagen interna no existe o, más precisamente, que aquello visto internamente, de hecho, no es una imagen. ${ }^{22}$ Sartre, por su parte, acepta la tesis de que no es posible contar las columnas del Panteón vivenciado en imagen, sin embargo, esto no se debe a una inexistencia aprehensiva de lo visto, sino que es producto de que el objeto es presentado en un plano significativo distinto al Panteón percibido, pues, en este caso, la construcción es imaginada. El que no podamos contar las columnas del Panteón imaginado se debe a que esta presencia se constituye en condición de ausente, es decir, esta "conciencia imaginante es, en efecto, conciencia de un objeto en imagen [el Panteón] y no conciencia de una imagen" (Sartre, 2005, p. 125).

\footnotetext{
22 "Alain deducirá como conclusión que la imagen no existe. No pensamos lo mismo; lo único que hemos querido es señalar el carácter paradójico de la imagen, atraer la atención sobre estas columnas que son actualmente el objeto de mi conciencia y que ni siquiera puedo tratar de contar" (Sartre, 2005, p. 127).
} 
| Artigo | Edmund Husserl y Jean-Paul Sartre: apuntes sobre conciencia de imagen, fantasía e imaginación | | Sergio González Araneda |

Es evidente, por tanto, que el Panteón aparece de manera diferente en una conciencia imaginativa que en una conciencia perceptiva, con todas las implicancias del caso tanto en un nivel ontológico, temporal o epistemológico. Sartre concluye:

No es verdad que, como dice Bergson, la imagen sea una "representación cuyas imágenes se yuxtaponen". Sin duda [...] una conciencia imaginante trata de alcanzar el objeto exterior en su exterioridad, es decir, en tanto que está formado por partes yuxtapuestas; pero en tanto que afectividad el objeto se da como un todo indiferenciado (2005, p. 127).

\section{COMENTARIO FINAL}

El principal objetivo que busca sostener Sartre en su reflexión sobre lo imaginario y el acto imaginativo es mostrar y sostener el fundamento y la forma en que la imaginación, por medio de su correlato noemático, lo imaginario, se presenta como superación de la

percepción y, por tanto, como posibilidad de re-significación del mundo presente dado en-sí (en soi). Es decir -y será la consecuencia más radical que alcanzará Sartre- la imaginación se presenta fundamentalmente como libertad: "la conciencia tiene que estar libre en relación a toda realidad particular, y esta libertad se tiene que poder definir con un 'estar-en-el-mundo' que es a la vez constitución y anonadamiento de este mundo" (2005, p. 156).

En virtud de lo anterior, la crítica sartreana apunta, como se ha mencionado al comienzo, hacia la constatación de una materia hylética subjetiva en el proceso de constitución de imágenes dentro de la teoría de Husserl. Esta materia supondría un substrato inerte, categorial, que le permitirá a Sartre igualar la reflexión husserliana con la filosofía kantiana.

De hecho, para Sartre, Husserl no habría dado solución a la actividad de la conciencia de producir imágenes, pues la limita a esta materia hylética subjetiva que la intención anima. Esto supone que la conciencia intencional se despliega sobre un suelo pasivo y subjetivo que Sartre identificará con la arquitectura kantiana de las categorías del entendimiento: "Aun cuando se concediera a Husserl que hay en la noesis un estrato hilético, no sería concebible cómo la conciencia puede trascender esta subjetividad hacia la objetividad" (Sartre, 1993, p. 27). De este modo, la teoría de Husserl no resulta "sensiblemente diferente de la de Kant. 
| Artigo | Edmund Husserl y Jean-Paul Sartre: apuntes sobre conciencia de imagen, fantasía e imaginación | | Sergio González Araneda |

Pues, en efecto, si mi Ego empírico no es más seguro que el del prójimo, Husserl ha conservado el sujeto trascendental, radicalmente distinto de aquél y harto parecido al sujeto kantiano" (1993, p. 306).

Con ello, descubrimos un problema fundamental, y es que la lectura, análisis y crítica de Sartre se limita a la etapa estática de la fenomenología husserliana, desconociendo su desarrollo genético y, aún más, en su crítica pasa por alto el lugar que ocupa la constitución temporal de la conciencia en el proceso de la creación intencional imaginativa. Por tanto, el conocimiento que alcanzó acerca de la conciencia la imagen y la phantasie en Husserl fue parcial y limitado.

No obstante, la principal reflexión de la teoría de lo imaginario en Sartre, a saber, descubrir el fundamento de la conciencia que imagina como completa libertad, no se ve empañado por su limitado conocimiento de Husserl. Por ello hemos intentado exponer una lectura exegética sobre ambos autores, poniendo de relieve sus puntos de encuentro y distancia a la luz del desarrollo filosófico de los términos. Finalmente, notamos cómo se abre el campo para futuras investigaciones que, por ejemplo, coloquen su atención en el cambio de método y objetivos que experimenta Sartre en su lectura de Husserl evidenciados en la transición de L'Imagination y L'Imaginaire, o la relación filosófica que existe entre la phantasie fenomenológica y la categoría de lo mágico, de la cual Sartre muestra interés desde la década de 1930. Estos temas, oscuros y complejos de afrontar, necesitan de un trabajo investigativo que muestre hasta qué grado la influencia de Husserl se extiende e influye en la consolidación de una filosofía fenomenológica francesa $y$, en particular, en el existencialismo fenomenológico sartreano.

\section{Referências Bibliográficas}

Alain. Système des Beaux-Arts. Saint Amand: NRF, 1963.

Bachelard, G. El aire y los sueños. E. de Champourcin (trad.). México: Fondo de Cultura Económica, 2012. 
| Artigo | Edmund Husserl y Jean-Paul Sartre: apuntes sobre conciencia de imagen, fantasía e imaginación | | Sergio González Araneda |

Chávez, Román. La imagen y sus conflictos: conciencia de imagen y presentación en Husserl. En Xolocotzi, Á. y Gibu, R. Imagen y sentido: Reflexiones fenomenológicas y hermenéuticas. México: Editorial Nautilium, 2016.

De Coorebyter, V. (2012). De Husserl à Sartre. La structure intentionnelle de l'image dans L'Imagination et L'Imaginaire, [En línea]. Methodos, $\mathrm{N}^{\circ}$ 12. Disponible en: doi.org/10.4000/methodos.2971 [Acceso el 15 de septiembre de 2020].

Husserl, E. Ideas relativas a una fenomenología pura y una filosofía fenomenológica. J. Gaos (trad.). México: Fondo de Cultura Económica, 1962

Husserl, E. Husserliana XXIII: Phantasie, Bildbewusstsein, Erinnerung. La Haya: Martinus Nijhoff, 1980.

Husserl, E. Investigaciones Lógicas II. J. Gaos y M. García Morente (trads.). Madrid: Alianza Editorial, 1999.

Husserl, E. Analyses concerning passive and active synthesis. A. Steinbock (trad.). Dordrecht: Springer Science+Business Media, 2001.

Husserl, E. (2016): “Sobre la teoría del arte” M. Rossano y R. Chávez (trads.). Acta Mexicana de Fenomenología, $\mathrm{N}^{\circ} 1$, pp. 179-188.

Leiva, R. Dos interpretaciones sobre la actividad analógica en la psicología y ontología fenomenológica de J.-P. Sartre: Distinción material o función analógica. Investigaciones Fenomenológicas, $\mathrm{N}^{\circ}$ 13, pp. 89-106, 2016.

Mori, N. The Image and the Real: A Consideration of Sartre's Early Views on Art. Aesthetics, $\mathrm{N}^{\circ} 16$, pp. 11-24, 2012.

Richir, M. Phénoménologie en esquisses. Nouvelles fondations. Grenoble: Editions Jérôme Millon, 2000.

Richir, M. Imaginación y phantasía en Husserl. P. Posada (trad.). Eikasia: revista de filosofía, №40, pp. 33-54, 2011. 
| Artigo | Edmund Husserl y Jean-Paul Sartre: apuntes sobre conciencia de imagen, fantasía e imaginación | | Sergio González Araneda |

Richir, M. Phantasie, imaginación e imagen. P. Posada (trad.). Investigaciones Fenomenológicas, $\mathrm{N}^{\circ}$, pp. 333-347, 2012.

Rubio, R. El lugar de la fenomenología en el debate de la reciente filosofía de la imagen. Veritas, $\mathrm{N}^{\circ} 33$, pp. 89-101, 2015.

Saraiva, M. M. L'imagination selon Husserl. The Hague: Martinus Nijhoff, 1970.

Sartre, J. P. El ser y la nada. J. Valmar (trad.). Buenos Aires: Editorial Losada, 1993

Sartre, J. P. La imaginación. C. Dragonetti (trad.). Madrid: Editorial Sarpe, 1984.

Sartre, J. P. Lo imaginario. M. Lamana (trad.). Buenos Aires: Editorial Losada, 2005.

Sepp, H. R. Creencia de ser en los análisis husserlianos de la conciencia de imagen. En: Pintos Peñaranda, M. y González López, J. Fenomenología y ciencias humanas. Santiago de Compostela: Universidad de Santiago de Compostela, 1998.

Recebido em: 11/04/2020 | Aprovado em: 08/07/2020 